\title{
Effect of Aerobic Training and Diet on Insulin Resistance and Quality of Life in Type II Diabetic Patients
}

\author{
Mohammad Rahimi Gh.R.1 PhD, Attarzadeh Hosseini S.R.* PhD \\ *Sport Physiology Department, Physical Education \& Sports Sciences Faculty, \\ Ferdowsi University of Mashhad, Mashhad, Iran \\ ${ }^{1}$ Sport Physiology Department, Physical Education \& Sports Sciences Faculty, \\ Ferdowsi University of Mashhad, Mashhad, Iran
}

\begin{abstract}
Aims: Self-controling and non-drug intervention methods such as aerobic activities and diet programs have a significant impact on insulin resistance and quality of life in type II diabetic patients. The purpose of this research was to investigate the effect of 12 weeks of aerobic training with diet on insulin resistance and quality of life in type II diabetic patients.

Materials \& Methods: In this quasi-experimental research in 2013-14, obese female with type II diabetes in Taybad City, Iran, were selected by achievable sampling method and were divided into aerobic training $(n=12)$ and aerobic training with diet $(n=11)$ groups. Aerobic training in both groups was performed in 36 sessions of exercise training; 3 sessions per week with an intensity of $50-70 \%$ heart rate reserve. In addition to aerobic training, the second group participated in diet that included $500 \mathrm{kcal}$ of energy less than the estimated daily energy requirement. Data were analyzed with SPSS 16 software by paired and independent $\mathrm{T}$ tests.

Findings: The levels of blood glucose, insulin and insulin resistance reduced significantly just in aerobic training with diet group $(\mathrm{p}<0.05)$ just the fasting blood sugar difference was significant between 2 groups $(\mathrm{p}=0.035)$. Also, there were significant differences between groups in subscales of role limitations due to physical health problems $(\mathrm{p}=0.001)$, role limitations due to emotional problems $(\mathrm{p}=0.002)$, social functioning $(\mathrm{p}=0.002)$, pain $(\mathrm{p}=0.001)$ and general health $(\mathrm{p}=0.002)$.

Conclusion: 12 weeks of aerobic training with diet lead to improvement in blood sugar, fasting insulin, insulin resistance and some subscales of quality of life in type II diabetic patients.
\end{abstract}

\section{Keywords}

Exercise [http://www.ncbi.nlm.nih.gov/mesh/68015444];

Diet [http://www.ncbi.nlm.nih.gov/mesh/68004032];

Insulin Resistance [http://www.ncbi.nlm.nih.gov/mesh/68007333];

Quality of life [http://www.ncbi.nlm.nih.gov/mesh/68011788];

Diabetes Mellitus, Type 2 [http://www.ncbi.nlm.nih.gov/mesh/68003924]

\footnotetext{
* Corresponding Author

Tel: +985138833910

Fax: +985138829580

Address: Sport Physiology Department, Physical Education \& Sports Sciences Faculty, Pardis of Ferdowsi University, Azadi Square, Mashhad, Iran. Postal Code: 48979-91779

attarzadeh@um.ac.ir

Received: October 25, 2015 Accepted: July 01, 2015 ePublished: December 15, 2015
} 


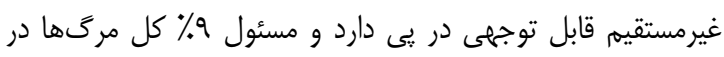

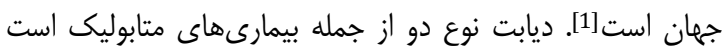

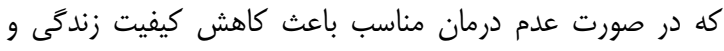

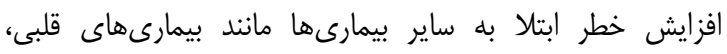

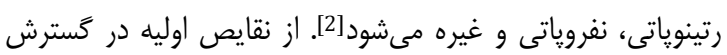

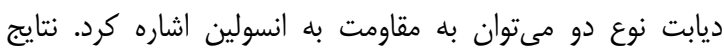
مطالعات نشان داده است كه مقاومت به انس انسولين در كسترش بيمارىهاى قلبى - عروقى نيز نقش مهمى دارد [3].

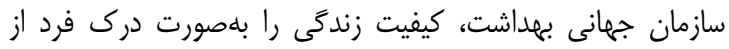

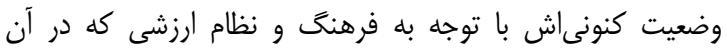

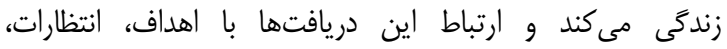

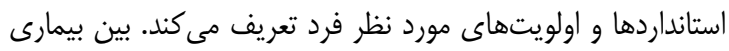

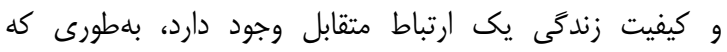

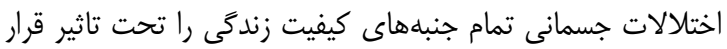

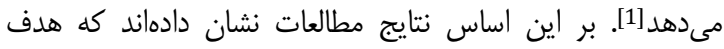

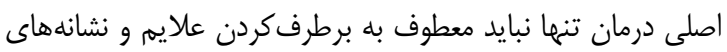

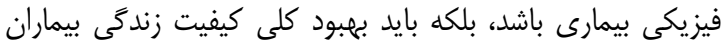

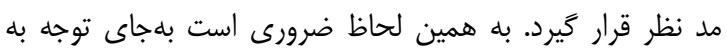

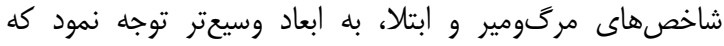

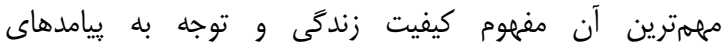
روانشناختى و روانى اجتماعى ناشى از بيمارى است [4].

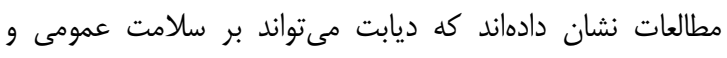

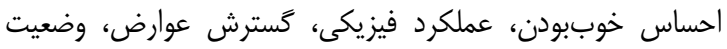

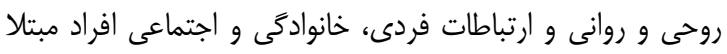

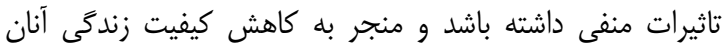

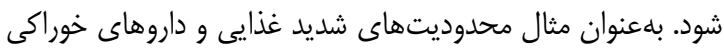

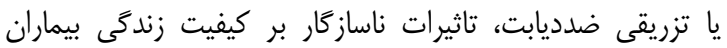

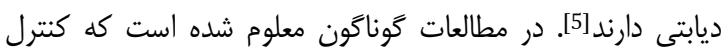

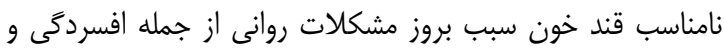

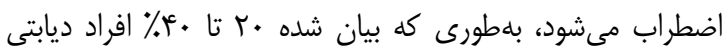

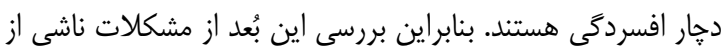

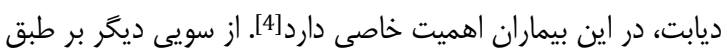

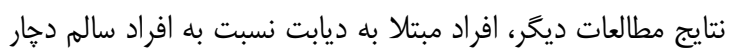

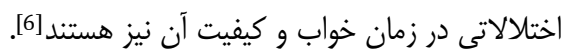

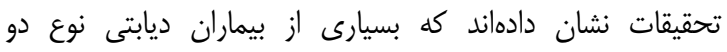

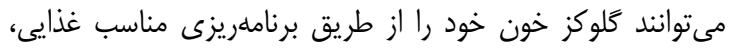

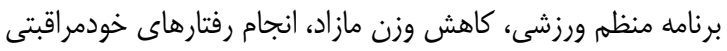

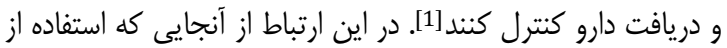

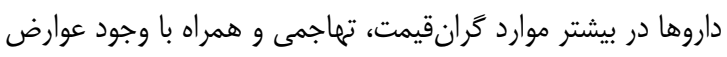

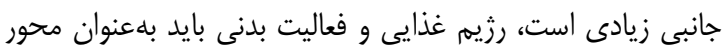

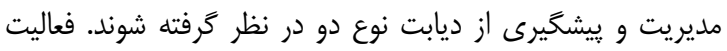

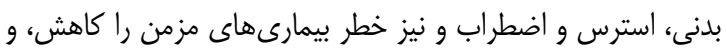

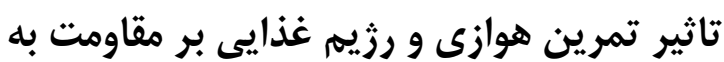

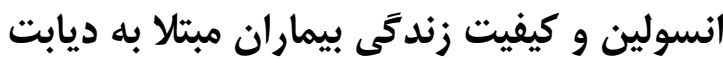

نوع دو

غلامرسول محمدر حيمى PhD

كروه فيزيولوزى ورزش، دانشكده تربيت بدنى و علوم مدوم ورزشى، دانشگاه فردوسى

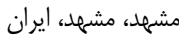

سيدر أ عطارز اده حسينى " PhD

كروه فيزيولوزى ورزش، دانشكده تربيت بدنى و علوم ورزشى، دادينى دانشعاه فردوسى

مشهر، مشهد، ايران

جكيده

اهداف: روشهاى خودكنترلى و مداخلات غيردارويى مثل فعاليتهاى

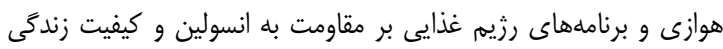

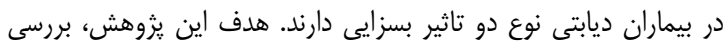

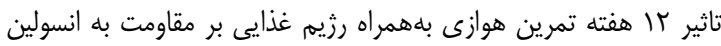

و كيفيت زندكى بيماران ديابتى نوع دو بود.

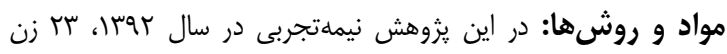

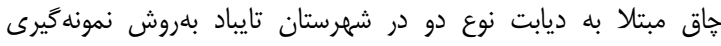

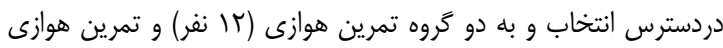

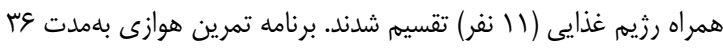

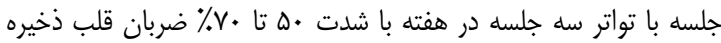

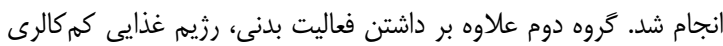

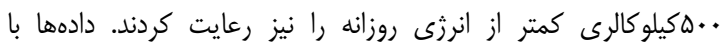

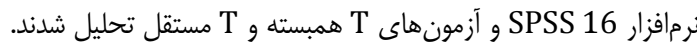
يافتهها: سطوح قند خون، انسولين ناشتا و شاخص مقاومت به انسولين

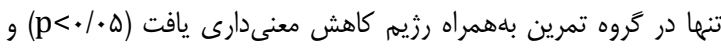

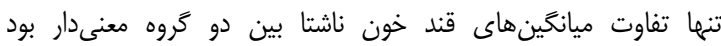

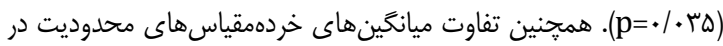

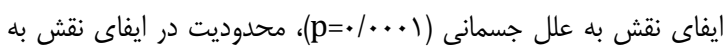

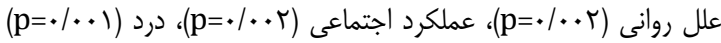

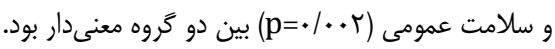

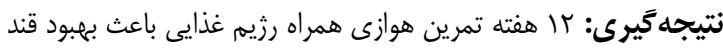

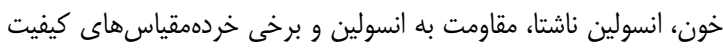

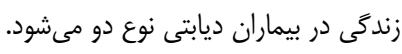

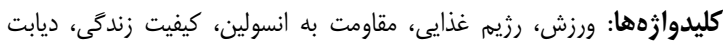
مليتوس نوع دوم

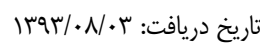

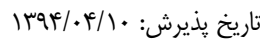
"نويسنده مسئول: attarzadeh@um.ac.ir

مقدمه

ديابت يكى از بيمارىهاى مزمن است كه سبب بروز مشكلات

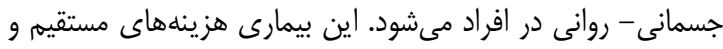
دوره rT، شماره ا، زمستان FaF

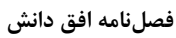


تاثير تمرين هوازى و رزيم غذايى بر مقاومت به انسولين و كيفيت زندكى بيماران مبتلا به ديابت نوع دو ه9

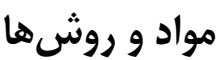

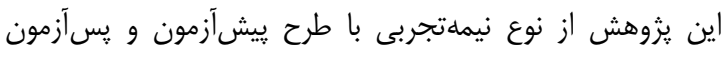

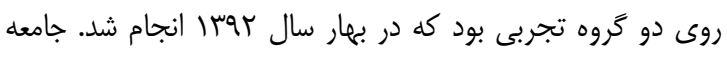

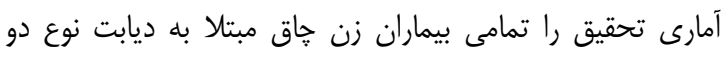

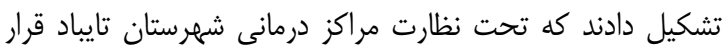

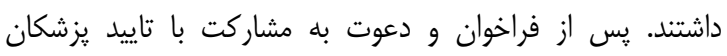

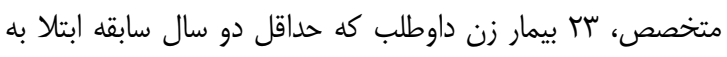

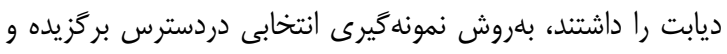

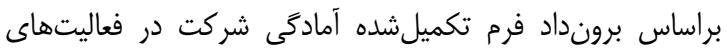

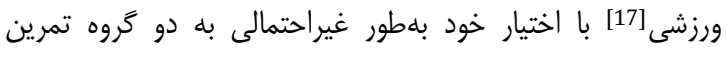

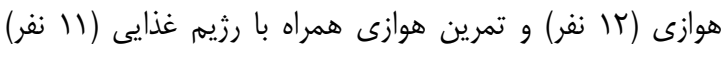

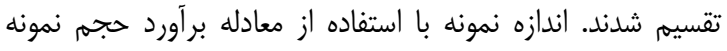

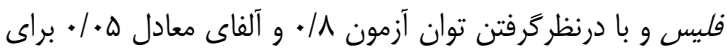

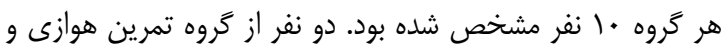

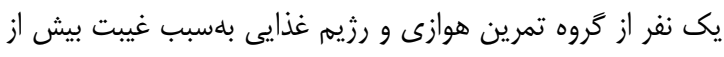

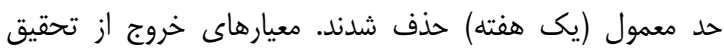

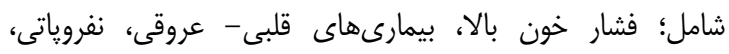

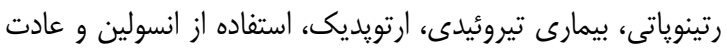

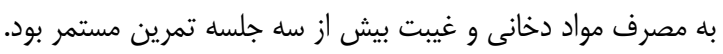

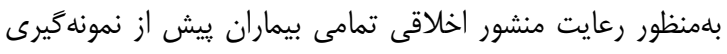

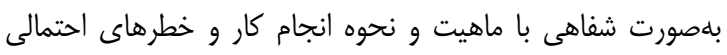

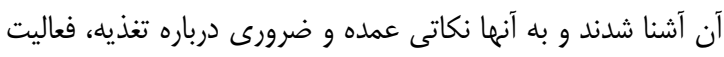

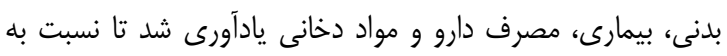

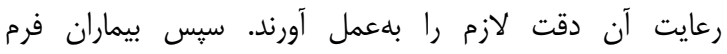

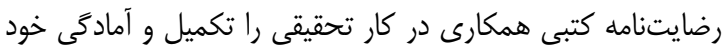

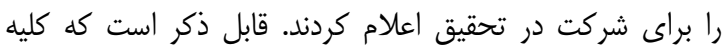

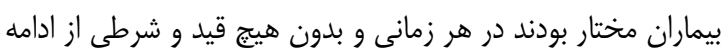
كار تحقيقى انصراف دهند.

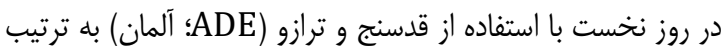

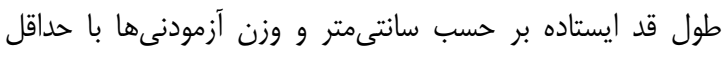

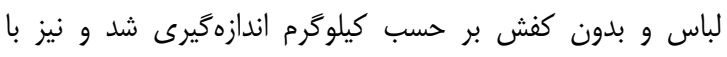

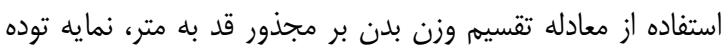

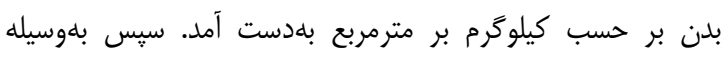

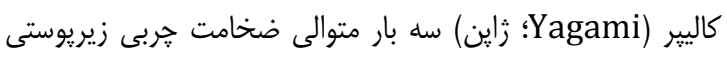

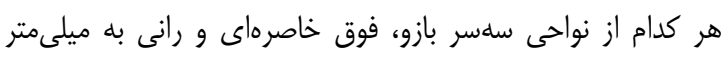

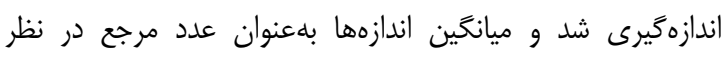

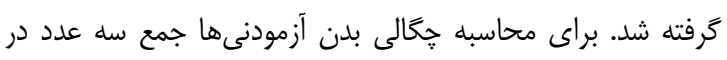

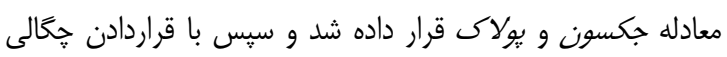

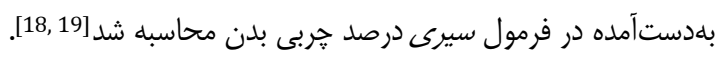

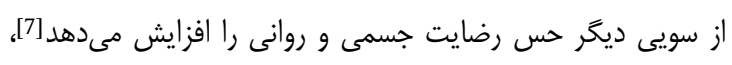

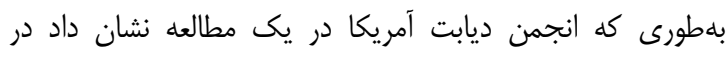

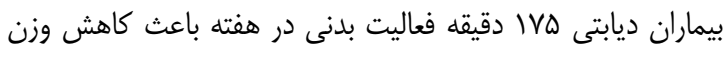

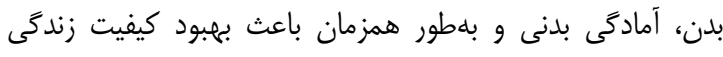

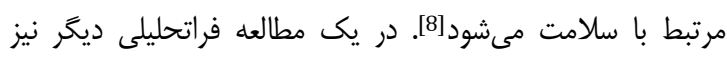

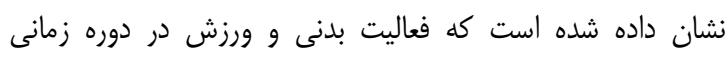

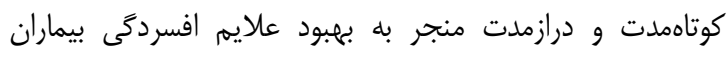

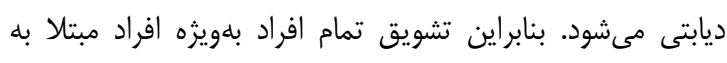

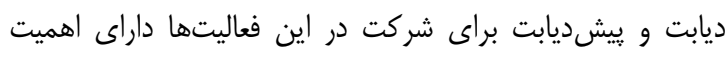

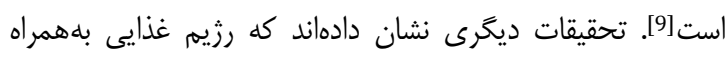

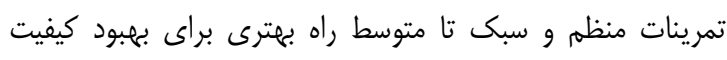

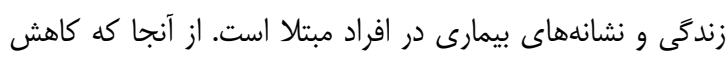

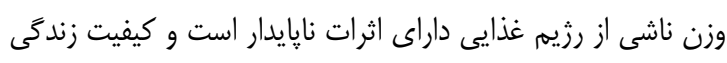

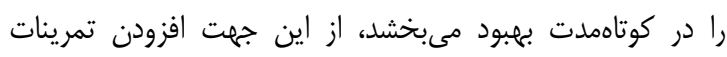

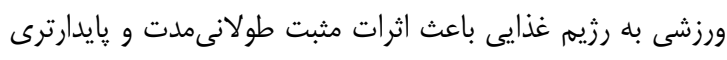
بر كيفيت زندگى و كنترل متابوليك مى شود[110,11].

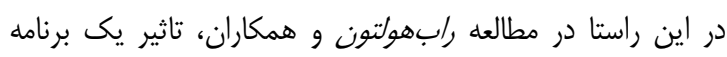

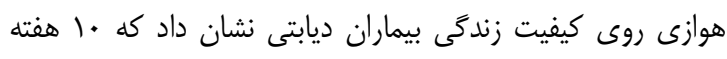

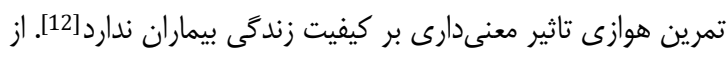

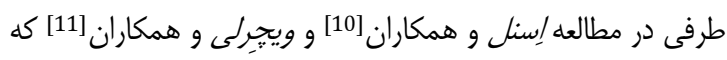

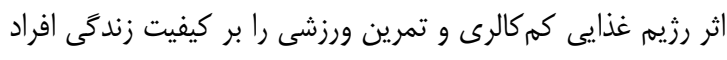

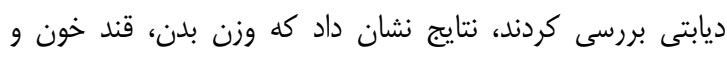

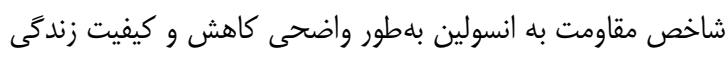

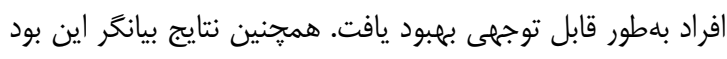

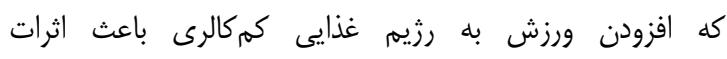

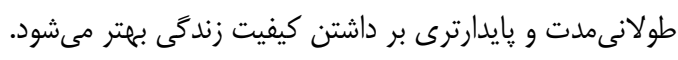

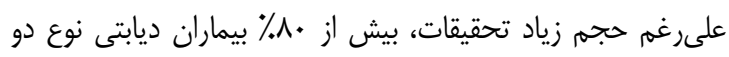

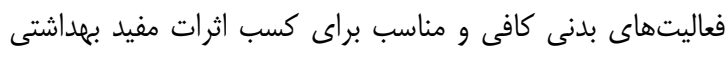

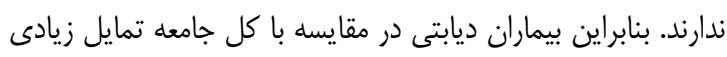

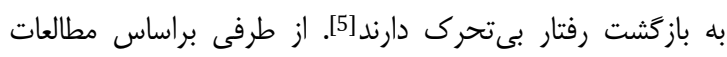

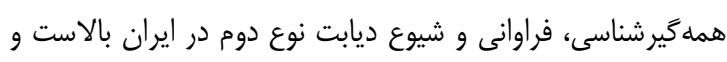

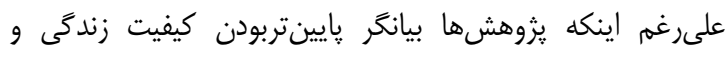

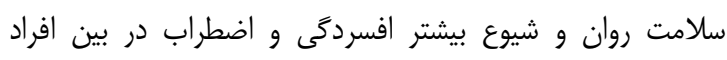

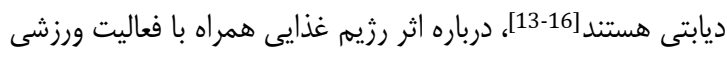

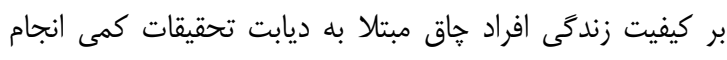

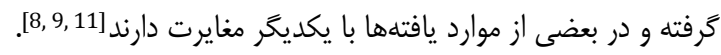

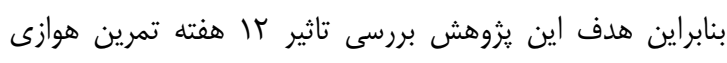

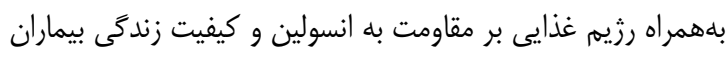

ديابتى نوع دو بود. 
بلروش كارونن محاسبه و در حين تمرين با ضربانسنج (POLAR)

ضربان قلب استراحت + [درصد مورد نظر ×(ضربان قلب استراحت ـ

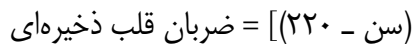

كيفيت زندگى كروهها با استفاده از يرسشنامه وستئوالى كيفيت

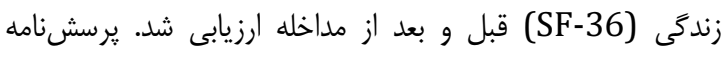

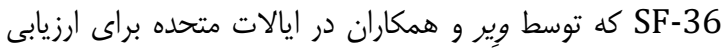

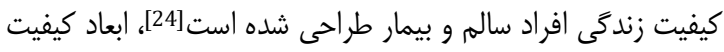

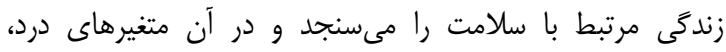

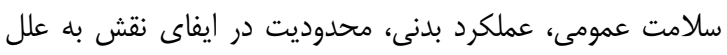
روانى، محدوديت در ايفاى نقش به به علل جسمانى مدانى، عملكرد

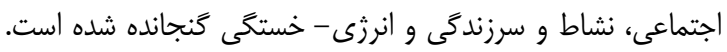

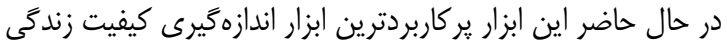

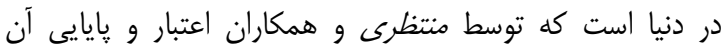

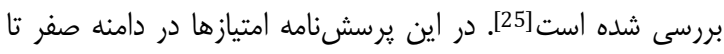

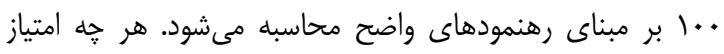
بالاتر باشد، نشاندهنده وضعيت بهترى است.

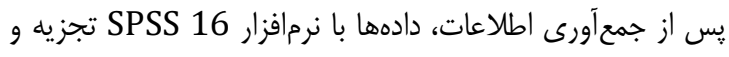

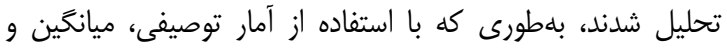

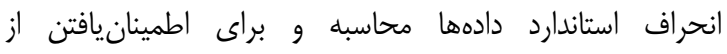

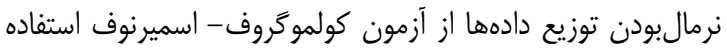

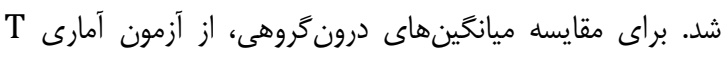
همبسته و براى مقايسه ميانخينهاى بين كَروهى از آزمون آمارى آمارى

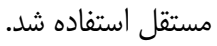

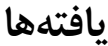

در كروه تمرين هوازى و رثيم غذايى و تمرين هوازى بهتتنهايى به

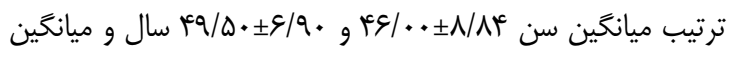

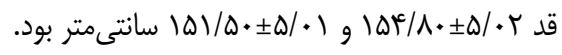

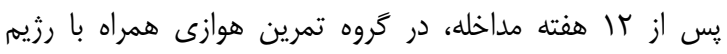
غذايى، ميانكين متغيرهاى قند خون، انسولين ناشتا و شاخص آنس

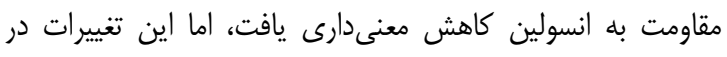

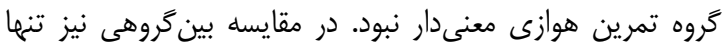

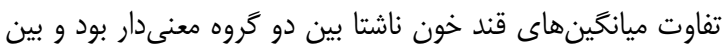

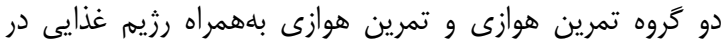

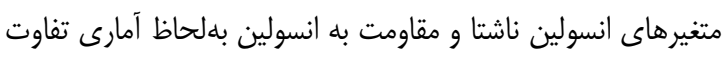
معنى دارى وجود نداشت. همجنين ميانكَين وزن، نمايه توده بدنى و و

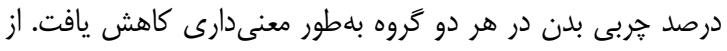

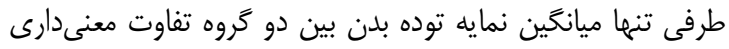

داشت (جدول ()).
SSF

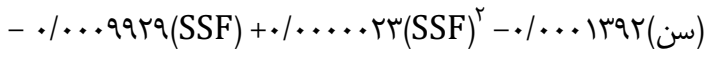
هُ جالى بدن

.

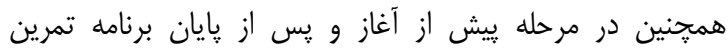

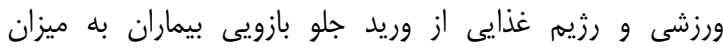

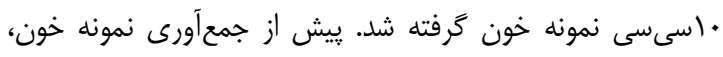

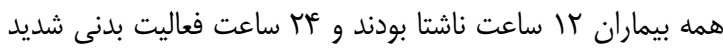

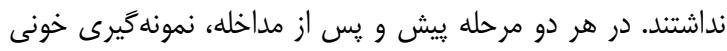

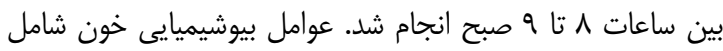

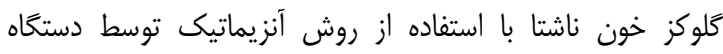

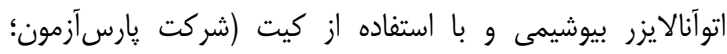

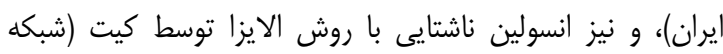

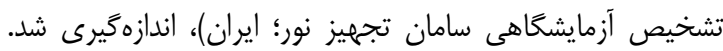

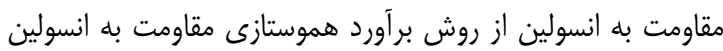
(HOMA-IR) ناشتايى سرم براساس فرمول زير محاسبه شد أنازئ:

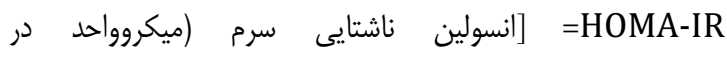

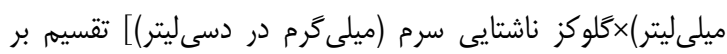

$r+\Delta \times) \Lambda$

سبس براى محاسبه حساسيت انسولين از نسبت عكس - HOMA

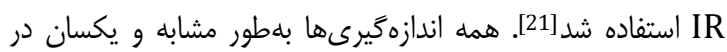

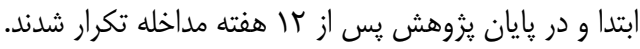

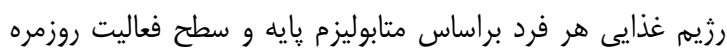

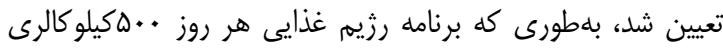

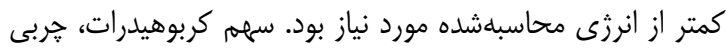

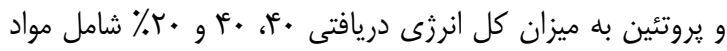

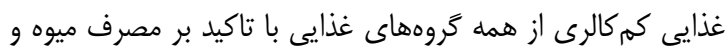

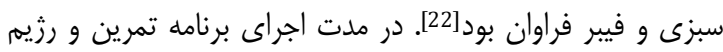

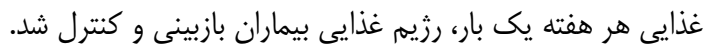
برنامه تمرين هوازى براساس راهنماى كالج آمريكايى طب نبان

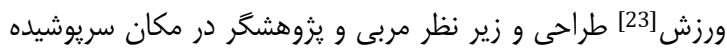

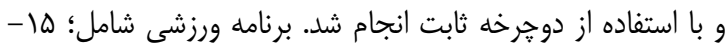

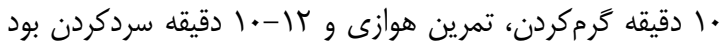

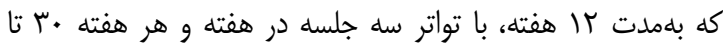

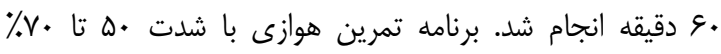

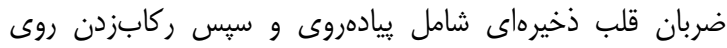

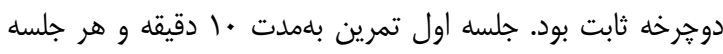

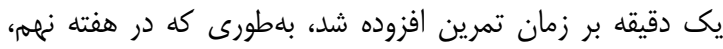

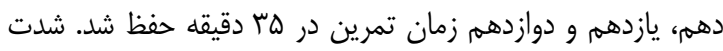

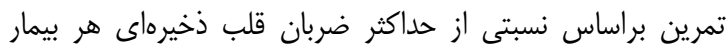


تاثير تمر ين هوازى و رزيم غذايى بر مقاومت به انسولين و كيفيت زندكى بيماران مبتلا به ديابت نوع دو اتو

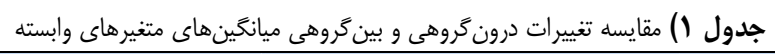

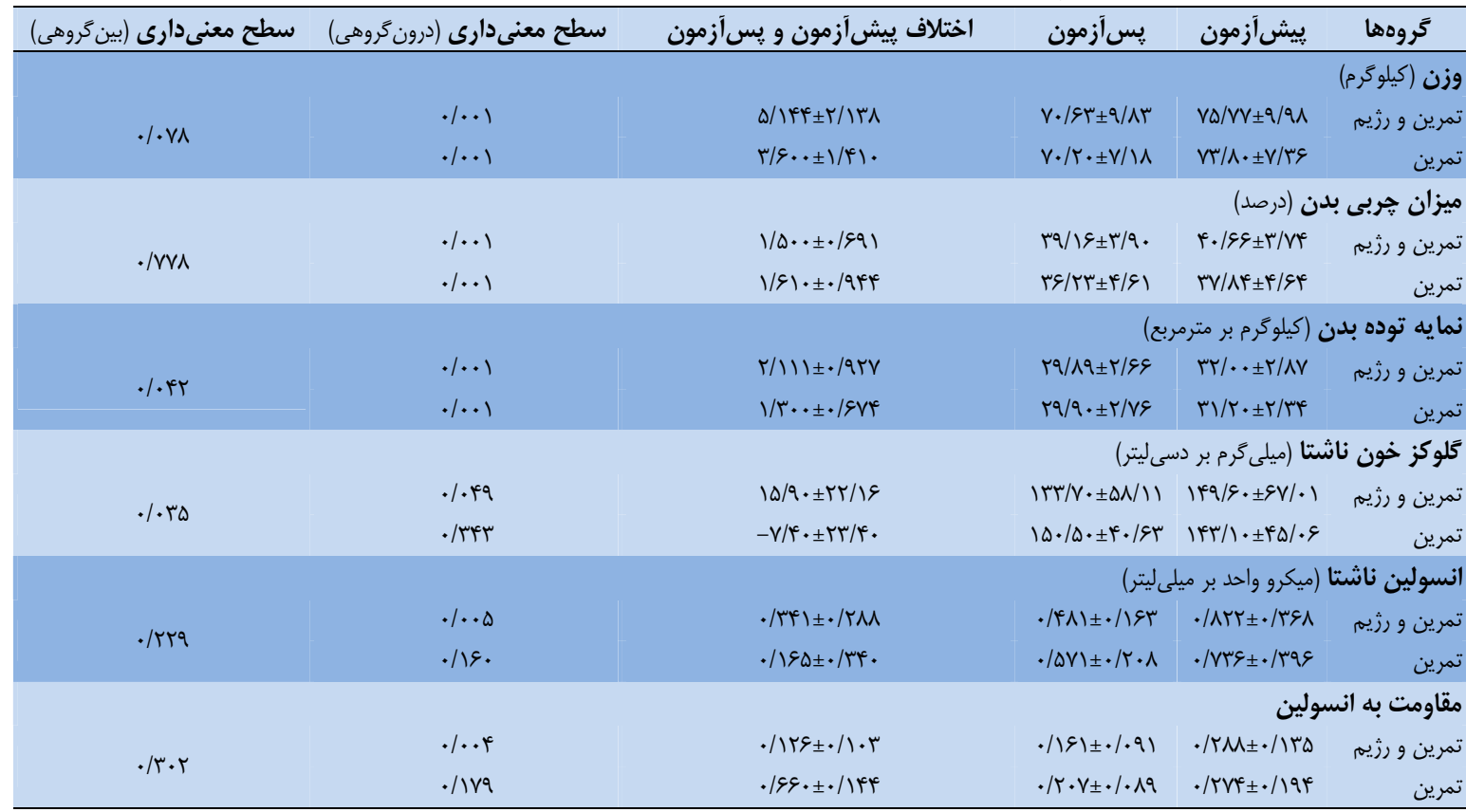

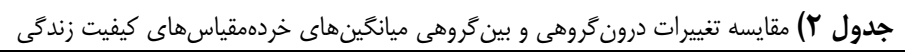

\begin{tabular}{|c|c|c|c|}
\hline سطح معنىدارى بين كَروهى & تمرين بهتنهايى (·( نفر) & تمرين همراه با رزيم (• انفر) & متغيرها \\
\hline.$|\cdots \cdot|$ & $\begin{array}{c}r \cdot / r \Delta \pm r q / r r \\
V r / \Delta r \pm r V / \Delta \mid \\
\cdot / \cdot r\end{array}$ & $\begin{array}{c}\Delta V / \Delta \Delta \pm Y q / I V \\
\mid q V / \Delta \Phi \pm F F / I V \\
. / \cdots 1\end{array}$ & 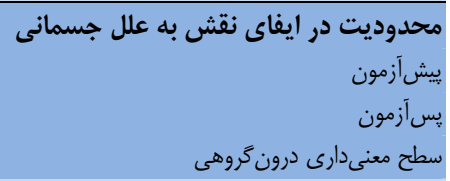 \\
\hline$\% r$ & $\begin{array}{c}V / \Delta I \pm \mid r / \cdot V \\
V T / Q T \pm T V / \Delta I \\
. / \cdots 1\end{array}$ & $\begin{array}{c}r V / \Delta T \pm T V / \Delta \mid \\
\mid \Psi Q / r \Lambda \pm T r / Q V \\
. \cdots 1\end{array}$ & 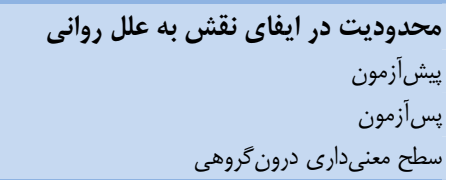 \\
\hline.$/ 10$ & $\begin{array}{c}V \cdot / \& \Delta \pm r \cdot / V r \\
q r / \Delta \Lambda \pm r / / r q \\
\cdot / 1 \cdot 1\end{array}$ & 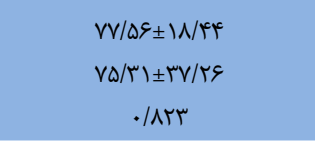 & سيش آزآزمون \\
\hline.$/$ fys & 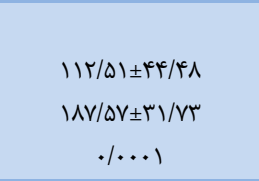 & 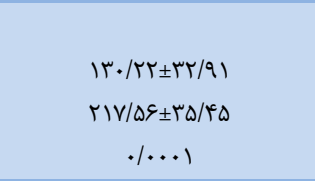 & نشاط و سيش آزمون \\
\hline ..$r r$ & $\begin{array}{c}|\Delta / r| \pm r \mid / \cdot \Lambda \\
\Delta r / \Delta Q \pm r \mid / M \\
\quad / \cdot r\end{array}$ & 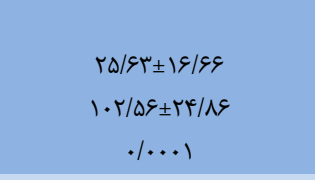 & 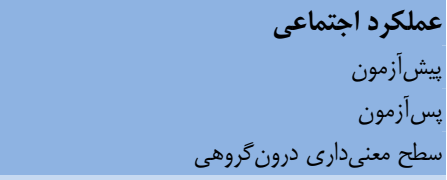 \\
\hline.$/ . .1$ & $\begin{array}{c}r \Delta / V I \pm T \& / A V \\
V T / Q T \pm T V / \Delta I \\
. / V I Q\end{array}$ & 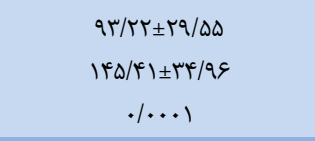 & سي سيش آزمون مون \\
\hline$\% r$ & $\begin{array}{c}r \Delta / \& \mid \pm r \varepsilon / A V \\
V T / \Delta \Delta \pm Y Y / \Delta 1 \\
. / .1\end{array}$ & 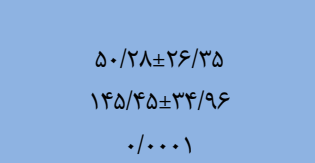 & 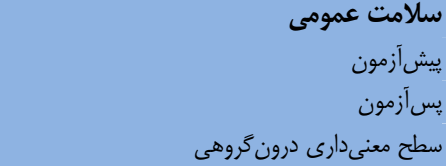 \\
\hline
\end{tabular}


نداشت]29]. در اين رابطه مى توان به مداخله ساير عوامل مانند؛ نوع،

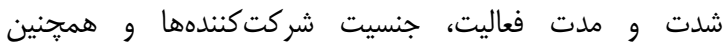
درنظرنكرفتن رزيم غذايى اشاره كرد. تحقيقات نشان مىدهند انقباض عضلانى دارئ ارداى يكى نقش شبه

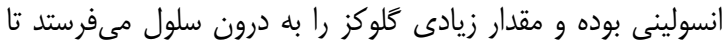

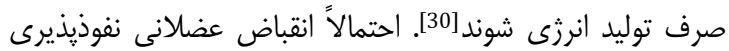

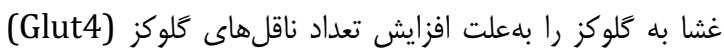
در غشاى بلاسمايى افزايش مىدهد. با انجام فعاليت ورزشى ميزان إنان

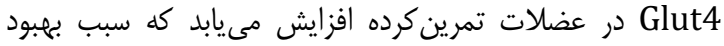

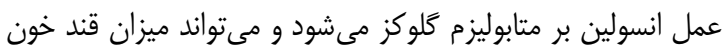

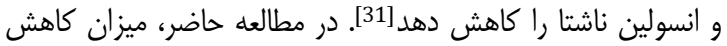

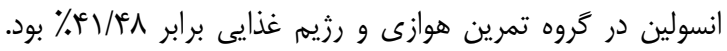

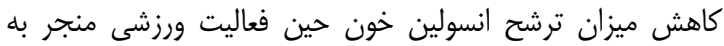

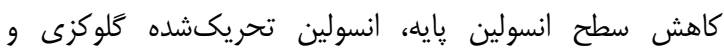
همجنين كاهش ميزان mRNA لازم براى توليد يروانسولين و

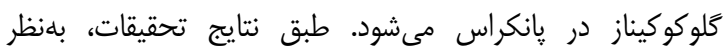

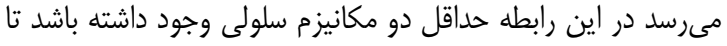

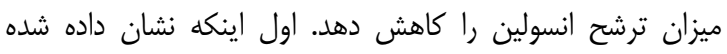
كاهش mRNA بروانسولينى نشانه كاهش سنتز انسولين در كبد

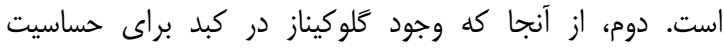
سلولهاى بتاى پانكراس به انسولين ضرورى است، كاهش ميزان

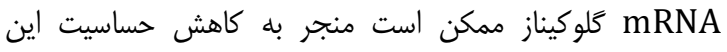

سلولها به انسولين شده و ميزان ترشح آن را كاهش دهان دهد [32.

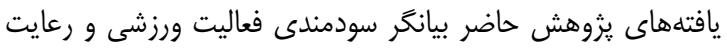

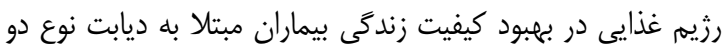

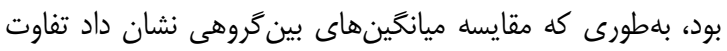

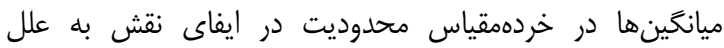

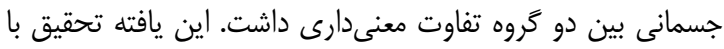

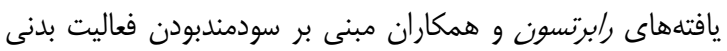

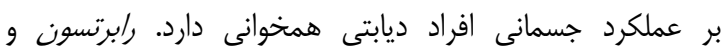

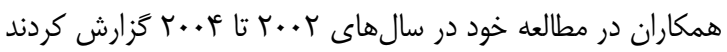

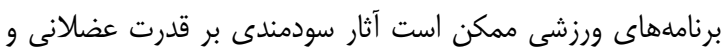

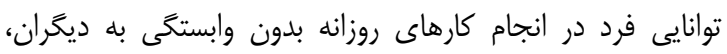

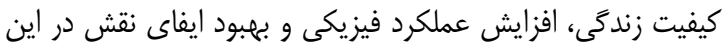
افراد بخذارد و اين نشاندهنده تاثير مثبت فعاليت ورزشى بر بر ابعاد

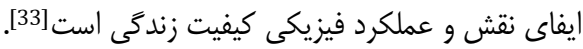

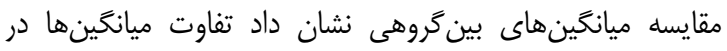

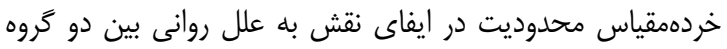

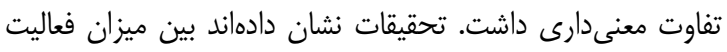

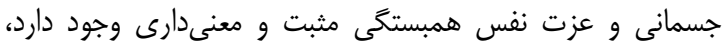

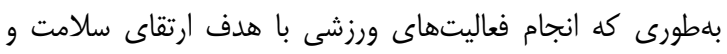

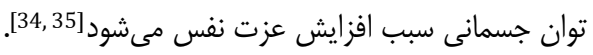

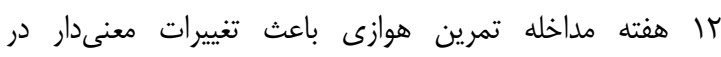

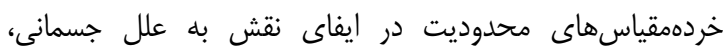
محدوديت در ايفاى نقش به علل روانى، نشاط و سرزندگىى، عملكرد

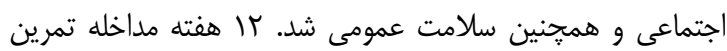

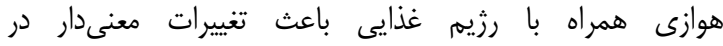
خردمقياسهاى محدوديت در ايفاى نقش به عله علل جسمانى،

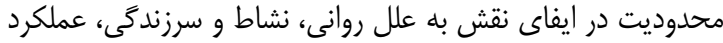
اجتماعى، درد و سلامت عمومى شد. همجنين ميانكَينهاى ابعاد

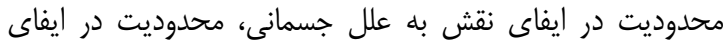

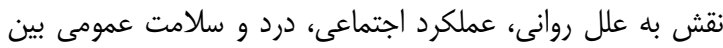
دو كروه تفاوت معنى دارى داشت (جدول rاع).

\section{بحث}

براساس نتايج اين يثوهش ميزان قند خون، انسولين ناشتا و

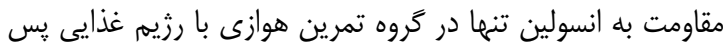

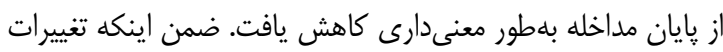

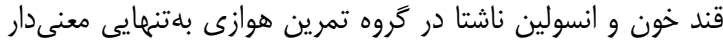

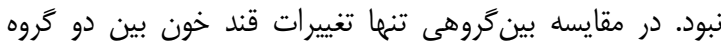

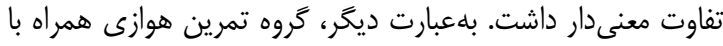

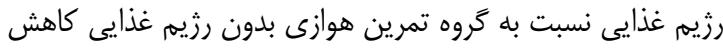
بيشترى در قند خون را تجربه كردند. تغييرات مقاومت به به انسولين

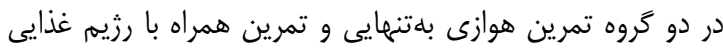

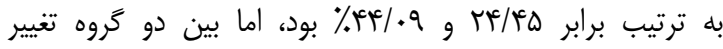

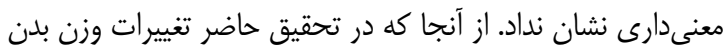

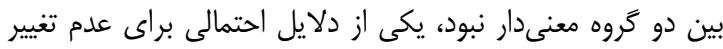

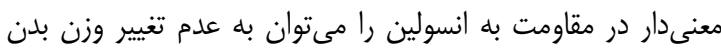

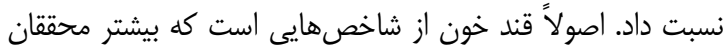

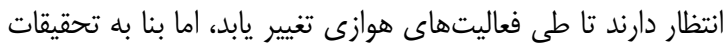

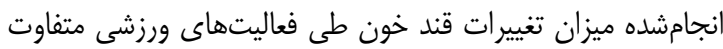

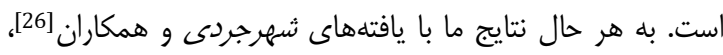

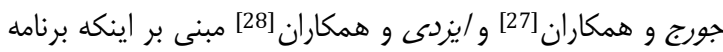
تمرين هوازى منجر به كاهش معنى دار كلوكز ناشتا و مقاومت بهان

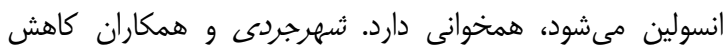

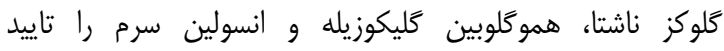

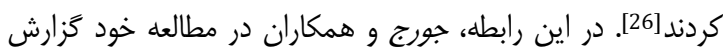
كردند تمرينات هوازى، مقاومتى و تركيبى منجر به كاهش كلون

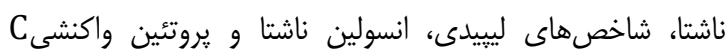

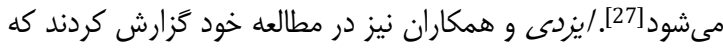

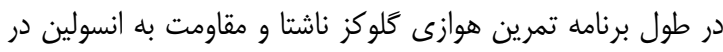

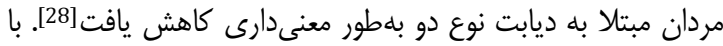

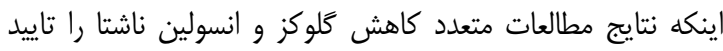
كردند، نتايج اين تحقيق با يافتههاى كوزا و همكاران همخوانى 


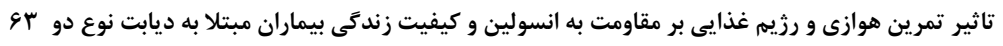

مىتوانست بر دقت نتايج يثوهش حاضر بيفزايد. از آنجا كه انجام

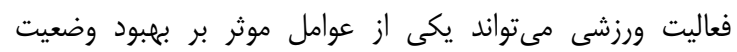

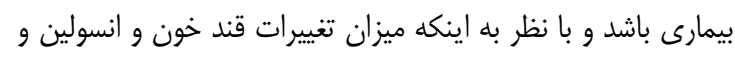

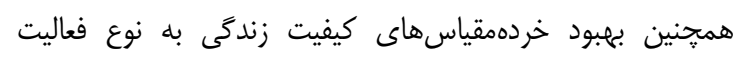

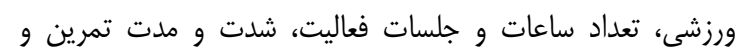

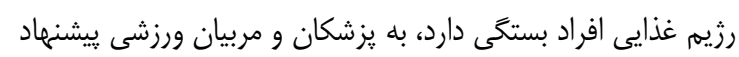

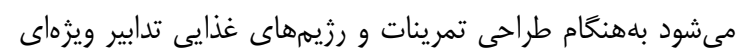

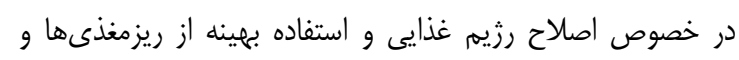
مصرف مواد غذايى مناسب بينديشند.

\section{نتيجه تيرى}

rا هفته تمرين ورزشى هوازى همراه رزيم غذايى مىتواند باعث بهبود قند خون، انسولين ناشتا، مقاومت به انسولين و برخى ازئ همراه خردهمقياسهاى كيفيت زندگى در بيماران ديابتى نوع دو شود، اما تمرين هوازى بهتنهايى اثرى بر بهبود اين فاكتورها ندارد. تشكر و قدردانى: از كليه بيمارانى كه در اين يثوهش شركت كردند و در انجام آن ما را يارى نمودند، تشكر و قدردانى مى فى لماييهم.

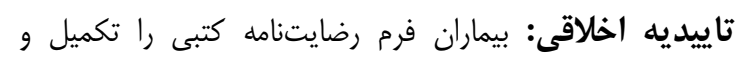
آمادگى خود را براى شركت در تحقيق اعلام كردند. تعارض منافع: موردى توسط نويسندكان گزارش نشده است. منابع مالى: اين مقاله منبع تامين مالى نداشته است.

منابع

1- Zimmet P. The burden of type 2 diabetes: are we doing enough? Diabetes Metab. 2003;29(4):6S9-18.

2- DeFronzo RA. Pathogenesis of type 2 diabetes mellitus. Med Clin North Am. 2004;88(4):787-835.

3- Misra A, Alappan NK, Vikram NK, Goel K, Gupta N, Mittal K, et al. Effect of supervised progressive resistance-exercise training protocol on insulin sensitivity, glycemia, lipids, and body composition in Asian Indians with type 2 diabetes. Diabetes Care. 2008;31(7):1282-7.

4- Kelley DE, Goodpaster BH. Effects of exercise on glucose homeostasis in Type 2 diabetes mellitus. Med Sci Sports Exerc. 2001;33(Suppl 6):S495-501.

5- Alavi NM, Ghofranipour F, Ahmadi F, Emami A. Developing a culturally valid and reliable quality of life questionnaire for diabetes mellitus. East Mediterr Health J. 2007;13(1):177-85.

6- Sadegh Ahari S, Arshi S, Iranparvar Alamdari M, Amani F, Siahpoush H. The effect of complications of diabetes type II on the quality of life in diabetic patients. J Ardebil Univ Med Sci. 2009;8(4):394-402. [Persian]

7- Chaput JP, Klingenberg L, Rosenkilde M, Gilbert JA, Tremblay A, SjödinA. Physical activity plays an important role in body weight regulation. J Obes. 2011;2011:360257.

8- Gram B, Christensen R, Christiansen C, Gram J. Effects of nordic walking and exercise in type 2 diabetes mellitus: A randomized controlled trial. Clin J Sport Med. 2010;20(5):355-61.
در مطالعه حاضر، تفاوت ميانخينها در خردهمقياسهاى عملكرد اجتماعى، درد بلدنى و سلامت عمومى نيز بين دو گروها تفاوه تفاوت

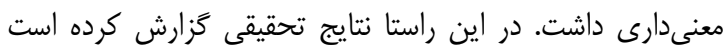

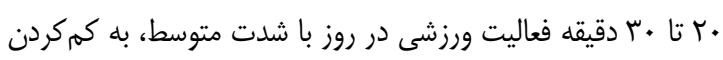
محدوديتهاى فعاليتى، افزايش ايفاى نقش و در نتيجه افزايش

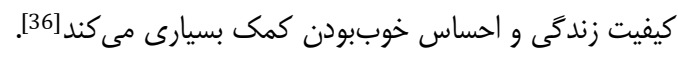

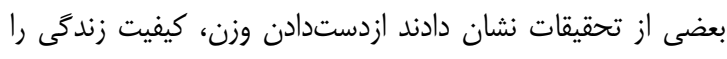
بهبود مىبخشد[37]. همجنين بيان شده است استفاده از انسولين بان

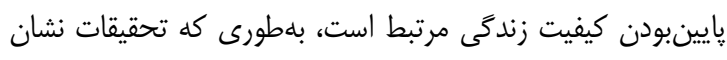

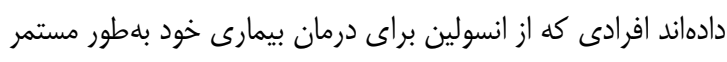

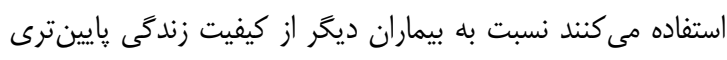

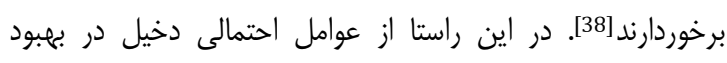

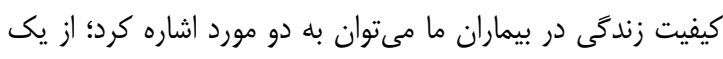

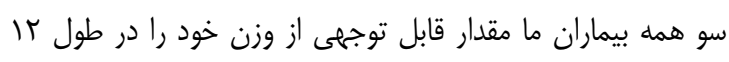
هفته تمرين و رثيم غذايى از دست دادند. از سويى ديخر هيج كدام

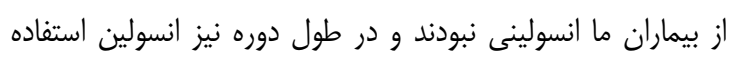
نمى كردند. مكانيزم خاصى كه منجر به اين تغييرات مثبت شاند شده

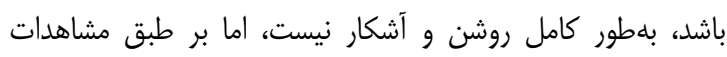
قبلى بيان شده است شركت در برنامههاى مشاوره در زمينه سبك

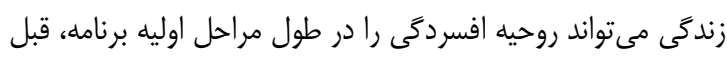

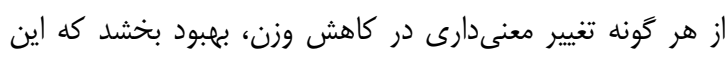

مى تواند به بهبود خودكنترلى و ادراك نسبت داده شود [39].

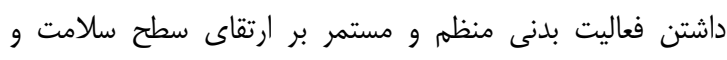

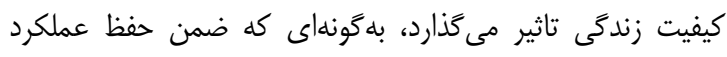
جسمى و ذهنى در سنين ييرى، بر طول عمر نيز افزوده و خطر ابتلا

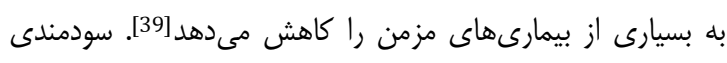

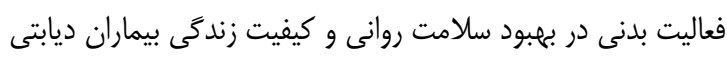

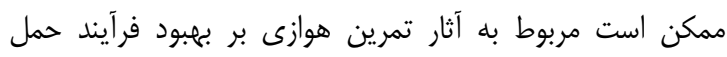
كلوكز و كاهش مقاومت به انسولين بافت عضلانى باشد، بلهطورى

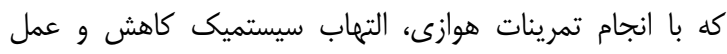
انسولين افزايش مىيابد و شاخص مقاومت به انسولين نيز كاهش

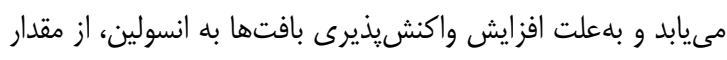

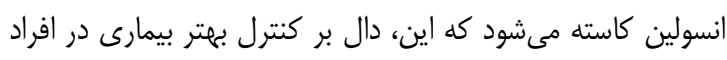
ديابتى نوع دو است [40]. از طرفى، از جمله سازوكارهاى روان روانى اثرات

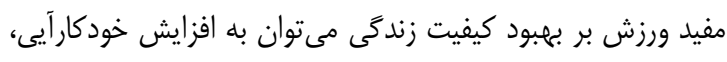

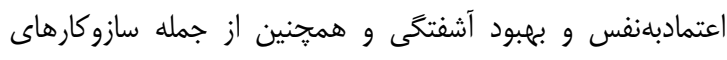
فيزيولوزيك به افزايش نورايىنفرين، تغيير در سنتز و متابوليزم سرتونين و اندورفينها اشاره كرد [26, 41]. از محدوديتهاى اين مطالعه مىتوان به عدم كنترل شيوه زندگى إنى

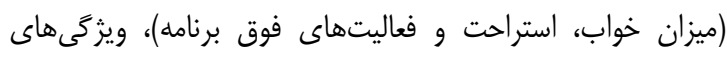

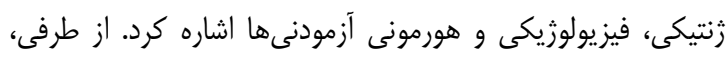

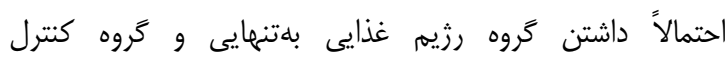


item selection. Med Care. 1992;30(6):473-83.

25- Montazeri A, Goshtasebi A, Vahdaninia M, Gandek B. The short form health survey (SF-36): Translation and validation study of the Iranian version. Qual Life Res. 2005;14(3):875-82.

26- Shahrjerdi Sh, Shavandi N, Sheikh-Hoseini R, Shahrjerd Sh. The effect of strengthening and endurance training on metabolic factors, quality of life and mental health in women with type $\Pi$ diabetes. J Shahrekord Univ Med Sci. 2010;12(3):85-93. [Persian]

27- Jorge ML, de Oliveira VN, Resende NM, Paraiso LF, Calixto A, Diniz AL, et al. The effects of aerobic, resistance, and combined exercise on metabolic control, inflammatory markers, adipocytokines, and muscle insulin signaling in patients with type 2 diabetes mellitus. Metabolism. 2011;60(9):1244-52.

28- Eizadi M, Karimi M, Kohandel M, Doaly H. Effect of aerobic exercise on serum leptin response and insulin resistance of patients with type 2 diabetes . J Qazvin Univ Med Sci. 2013;16(4):33-9. [Persian]

29- Cauza E, Hanusch-Enserer U, Strasser B, Ludvik B, Metz-Schimmerl S, Pacini G, et al. The relative benefits of endurance and strength training on the metabolic factors and muscle function of people with type 2 diabetes mellitus. Arch Phys Med Rehabil. 2005;86(8):1527-33.

30- Smith DW, McFall SL. The relationship of diet and exercise for weight control and the quality of life gap associated with diabetes. J Psychosom Res. 2005;59(6):385-92.

31- Brown GC, Brown MM, Sharma S, Brown H, Gozum M, Denton P. Quality of life associated with diabetes mellitus in an adult population. J Diabetes Complications. 2000;14(1):18-24.

32- Shobhana R, Rama Rao P, Lavanya A, Padma C, Vijay V, Ramachandran A. Quality of life and diabetes integration among subjects with type 2 diabetes. J Assoc Physicians India. 2003;51:363-6.

33- Khoshbin S, Ghosy A, Farahani A, Motlagh M. Guides to promote active lifestyles in old age. Tehran: Tandis Publications; 2007. [Persian]

34- Schmidt D, Schoettler B. Sport the elders. Material for sports in North $\mathrm{Rh}$ ine Westphalia 46. Duesseldorf: MAGS; 1996.

35- Hasan Pourdehkordy A, Masodi R, Naderi Poor A, Pourmirza Kalhori R. The effect of exercise on quality of life for the elderly in shahrekord. Salmand. 2008;6(2):437-44. [Persian]

36- Chen YM, Li Y. Safety and efficacy of exercise training in elderly heart failure patients: A systematic review and meta-analysis. Int J Clin Pract. 2013;67(11):1192-8.

37- Zhang X, Norris SL, Chowdhury FM, Gregg EW, Zhang $P$. The effects of interventions on health-related quality of life among persons with diabetes: a systematic review. Med Care. 2007;45(9):820-34.

38- Rubin RR, Peyrot M. Quality of life and diabetes. Diabetes Metabol Res Rev. 1999;15(3):205-18.

39- Lavie CJ, Thomas RJ, Squires RW, Allison TG, Milani RV. Exercise training and cardiac rehabilitation in primary and secondary prevention of coronary heart disease. Mayo Clin Proc. 2009;84(4);373-83.

40- Ravasi AA, Aminian Razavi T, Gaeini A, Hamediniya $M$, Haghighi AH. Effects of endurance training on proinflammatory cytokines and insulin resistance in obese men. Harekat. 2005;28(2):31-49. [Persian]

41- Dishman RK, Renner KJ, Youngstedt SD, Reigle TG, Bunnell BN, Burke KA, et al. Activity wheel running reduces escape latency and alters brain monoamine levels after footshock. Brain Res Bull. 1997;42(5):399406.
9- Reid RD, Tulloch HE, Sigal RJ, Kenny GP, Fortier M, McDonnell L, et al. Effects of aerobic exercise, resistance exercise or both, on patient-reported health status and well-being in type 2 diabetes mellitus: A randomized trial. Diabetologia. 2010;53(4):632-40.

10- Snel M, Sleddering MA, Vd Peijl ID, Romijn JA, Pijl H, Meinders AE, et al. Quality of life in type 2 diabetes mellitus after a very low calorie diet and exercise. Eur J Intern Med. 2012;23(2):143-9.

11- Wycherley TP, Marshall Clifton P, Noakes M, Brinkworth GD. Weight loss on a structured hypocaloric diet with or without exercise improves emotional distress and quality of life in overweight and obese patients with type 2 diabetes. J Diabetes Investig. 2014;5(1)94-8.

12- Holton DR, Colberg SR, Nunnold T, Parson HK, Vinik AI. The effect of an aerobic exercise training program on quality of life in type 2 diabetes. Diabetes Educ. 2003;29(5):837-46.

13- Paschalides C, Wearden AJ, Dunkerley R, Bundy C, Davies R, Dickens CM. The associations of anxiety, depression and personal illness representations with glycaemic control and health-related quality of life in patients with type 2 diabetes mellitus. J Psychosom Res. 2004;57(6):557-64.

14- Undén AL, Elofsson S, Andréasson A, Hillered E, Eriksson I, Brismar K. Gender differences in self-rated health, quality of life, quality of care, and metabolic control in patients with diabetes. Gend Medi. 2008;5(2):162-80.

15- Chagh R, Manoudi F, Benhima I, Asri F, Tazi I. Association between diabetes and depression. Eur Psychiatry. 2008;23(Suppl 2):S245.

16- Egede LE, Ellis C. Diabetes and depression: Global perspectives. Diabetes Res Clin Pract. 2010;87(3):302-12. 17- Alberti KG, Zimmet PZ. Definition, diagnosis and classification of diabetes mellitus and its complications. Part 1: diagnosis and classification of diabetes mellitus provisional report of a WHO consultation. Diabet Med. 1998;15(7):539-53.

18- Siri WE. Body composition from fluid spaces and density: analysis of methods. Nutrition. 1993;9(5):480-91. 19- Jackson AS, Pollock ML, Ward A. Generalized equations for predicting body density of women. Med Sci Sports Exerc. 1980;12(3):175-81.

20- Shidfar F, Rezaei Kh, Hosseini Esfahani Sh, Heydari I. The effects of vitamin $\mathrm{E}$ on insulin resistance and cardiovascular diseases risk factors in metabolic syndrome. Iran J Endo Metab. 2009;10(5):445-54. [Persian]

21- Skrha J, Haas T, Sindelka G, Prázný M, Widimský J, Cibula D, et al. Comparison of the insulin action parameters from hyperinsulinemic clamps with homeostasis model assessment and QUICKI indexes in subjects with different endocrine disorders. J Clin Endocrinol Metab. 2004;89(1):135-41.

22- Ryan MC, Abbasi F, Lamendola C, Carter S, McLaughlin TL. Serum alanine aminotransferase levels decrease further with carbohydrate than fat restriction in insulinresistant adults. Diabetes Care. 2007;30(5):1075-80.

23- Pollock M, Gaesser GA, Butcher JD, Després JP, Dishman RK, Franklin BA, et al. American College of Sports Medicine Position Stand, The recommended quantity and quality of exercise for developing and maintaining cardiorespiratory and muscular fitness, and flexibility in healthy adults. Med Sci Sports Exerc. 1998;30(6):975-91.

24- Ware JE Jr, Sherbourne CD. The MOS 36-item shortform health survey (SF-36). I. Conceptual framework and 